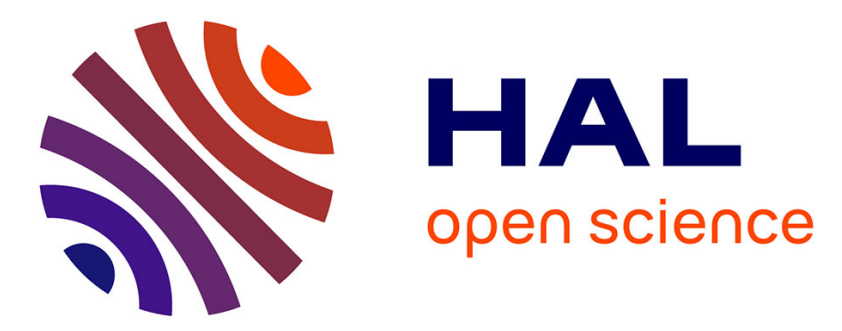

\title{
Microstructure evolution in bulk and surface states of chromium rich nickel based cast alloys reinforced by hafnium carbides after exposure to high temperature air
} Patrice Berthod, Elodie Conrath

\section{- To cite this version:}

Patrice Berthod, Elodie Conrath. Microstructure evolution in bulk and surface states of chromium rich nickel based cast alloys reinforced by hafnium carbides after exposure to high temperature air. Materials at High Temperatures, 2014, 31 (3), pp.266-273. 10.1179/1878641314Y.0000000023 . hal02553782

\author{
HAL Id: hal-02553782 \\ https://hal.science/hal-02553782
}

Submitted on 24 Apr 2020

HAL is a multi-disciplinary open access archive for the deposit and dissemination of scientific research documents, whether they are published or not. The documents may come from teaching and research institutions in France or abroad, or from public or private research centers.
L'archive ouverte pluridisciplinaire HAL, est destinée au dépôt et à la diffusion de documents scientifiques de niveau recherche, publiés ou non, émanant des établissements d'enseignement et de recherche français ou étrangers, des laboratoires publics ou privés. 


\title{
Microstructure evolution in the bulk and surface states of chromium-rich nickel-based cast alloys reinforced by hafnium carbides after exposure to high temperature in air
}

\author{
Patrice Berthod, Elodie Conrath \\ Institut Jean Lamour, Department N²: Chemistry and Physic of Solids and Surfaces \\ Team "Surface and interface, chemical reactivity of materials" \\ Faculty of Sciences and Techniques, Nancy - University, \\ B.P. 70239, 54506 Vandoeuvre-lès-Nancy - France \\ E-mail Address: patrice.berthod@univ-lorraine.fr
}

Postprint of the article Materials at High Temperatures 2014 VOL 31 NO 3 266-273.

DOI 10.1179/1878641314Y.0000000023

\begin{abstract}
Three alloys based on nickel, rich in chromium (25wt.\%) and containing varied quantities of carbon, 0.25 and $0.50 \mathrm{wt} . \%$, and of hafnium, 3.7 and $5.6 \mathrm{wt} . \%$, elaborated by casting were subjected to a $46 \mathrm{~h}$-long exposure to $1200^{\circ} \mathrm{C}$ in dry industrial air. This aimed to specify the thermal stability of their carbide interdendritic network and to discover their general behaviour in high temperature oxidation. The hafnium carbides slightly decreased in volume fraction but their fragmentation was rather limited. In contrast chromium carbides appeared in the two alloys which initially contained exclusively $\mathrm{HfC}$, which may result in a decrease in refractoriness. These carbides evolution were responsible of a moderate lowering of room temperature hardness. The behaviour in high temperature oxidation of the three alloys was very good, despite the unusually high contents in hafnium. All were chromia-forming, although oxidation of $\mathrm{Hf}$ led to $\mathrm{HfO}_{2}$ islands in the external scale and in the subsurface. To resume, the behaviour of these three alloys showed that the HfCcontaining $\mathrm{Ni}-25 \mathrm{Cr}$ family is potentially interesting for applications at very high temperatures.
\end{abstract}

Keywords: cast nickel alloys, hafnium carbides, high temperature, bulk microstructure, oxidation, hardness 


\section{Introduction}

In the past decades the cast superalloys based on nickel and reinforced by carbides were among the more often used metallic materials for high temperature service [1], in competition with cobalt-based alloys which are also often carbidesstrengthened [2]. The resistance of these high temperature alloys against hot corrosion was the most often achieved by introducing several tens percents of chromium [3]. Nowadays the most efficient nickel-based superalloys are the $\gamma / \gamma^{\prime}$ single crystal nickel-based superalloys for high temperature applications [4] in which the reinforcing phase is the intermetallic compound $\mathrm{Ni}_{3} \mathrm{Al}$ or more generally $(\mathrm{Ni}, \mathrm{Fe}$, $\mathrm{Co})_{3}(\mathrm{Al}, \mathrm{Ti} \mathrm{Ta}, \mathrm{Nb}$ ). Many of them contain several percents of chromium but the resistance against high temperature oxidation of these superalloys - when not coated - is essentially due to aluminium which allows forming a protective continuous alumina scale $[3,5]$.

For applications in which oxidation by gases are not the single mode of alloys' chemical deterioration but corrosion by molten substances may also occur, chromium must be present in significant quantities in the chemical composition of the alloys [ 3 , 5]. These ones cannot be thus mechanically reinforced by $\mathrm{Ni}_{3} \mathrm{Al}$ compounds, the presence of which necessarily limit the chromium contents, but by solid solution hardening (not always sufficient) or by carbides again. The chromium carbides featuring among the historically first used ones - are not stable enough in case of very high temperatures of service, typically $1200^{\circ} \mathrm{C}$. Other frequently used carbides, as the tantalum ones, resist more efficiently at high temperature against coarsening and volume fraction decrease [6]. Unfortunately $\mathrm{TaC}$ are not stable in nickel-based alloys in presence of high quantity of chromium, with as consequence a disappearance of the rare $\mathrm{TaC}$ carbides formed at solidification for the benefit of chromium carbides more stable than them (inversely to what generally observed in cobalt-based superalloys $[7,8])$. Other MC carbides, less common than the $\mathrm{TaC}$ ones, can be considered for reinforcing cast chromium-rich nickel-based alloys, as the HfC ones. Indeed, these carbides, which were earlier successfully obtained with a script-like eutectic shape in the interdendritic spaces [9] in Cr-rich Co-based cast alloys in which they demonstrated an interesting stability at very high temperature in terms of volume fraction as well as of morphology, have recently shown the same shapes, locations and high volume fractions in Cr-rich Ni-based alloys [10]. 
25wt.\%Cr-containing nickel-based alloys and containing several tenths weight percents of carbon, 0.25 and $0.50 \mathrm{wt} . \% \mathrm{C}$, and several percents of hafnium, 3.72wt.\% and $5.58 \mathrm{wt} . \% \mathrm{Hf}$, were thus obtained with a potentially interesting microstructure, with only - or at least predominantly - $\mathrm{HfC}$ carbides. In the case of the alloy containing $0.25 \mathrm{C}$ and $3.72 \mathrm{Hf}$, it was notably wished to respect the atomic equality between these two elements for favouring the exclusive appearance of $\mathrm{HfC}$ carbides. But the stability of these $\mathrm{HfC}$ carbides at very high temperature remains to be tested to start formulating hypotheses about the high temperature mechanical behaviour of such alloys. In parallel, since hafnium is the most often added to superalloys in much smaller quantities to improve the high temperature oxidation of superalloys in terms of oxidation rate or oxide scales adherence [11], its presence in so high quantities may greatly influence the high temperature oxidation behaviour of these new alloys and this no necessarily in the best direction...

In this work, the three $25 \mathrm{wt}$ \% Cr-containing Ni-based alloys recently obtained with significant, and even exclusive, presence of interdendritic $\mathrm{HfC}$ carbides were exposed for several tens of hours in a simple oxidant atmosphere, dry air, and at a chosen high temperature: $1200^{\circ} \mathrm{C}$, typical temperature at which such alloys are supposed to be used in case of good behaviour. The objectives were to characterize with this single test, the microstructure changes, notably concerning the natures and morphologies of the $\mathrm{HfC}$ carbides, and the deterioration by hot oxidation of the samples' surface and even of the whole alloy in case of catastrophic oxidation.

\section{Experimental}

\subsection{The studied alloys}

In a recent work [10] three $40 \mathrm{~g}$-weighing compact ingots of Hf-rich nickelbased alloys were elaborated by High Frequency induction melting in an inert atmosphere of $300 \mathrm{mbars}$ Ar. The initially wished chemical compositions of the three studied alloys, named "NiHf1", "NiHf2" and "NiHf3", were respectively Ni(bal.)-25Cr0.25C-3.72Hf, Ni(bal.)-25Cr-0.50C-3.72Hf and Ni(bal.)-25Cr-0.50C-5.58Hf (in wt.\%). The chemical compositions which were really obtained are Ni(bal.)-26Cr-0.25C4.4Hf, $\mathrm{Ni}$ (bal.)-26Cr-0.50C-4.8Hf and $\mathrm{Ni}$ (bal.)-25Cr-0.50C-6.6Hf, as specified by Energy Dispersion Spectrometry (EDS) measurements (only $\mathrm{Ni}, \mathrm{Cr}$ and $\mathrm{Hf}$; $\mathrm{C}$ : too light element, content supposed respected). 
The as-cast microstructures of the obtained alloys, observed with a JEOL JSM6010LA scanning electron microscope (SEM) in back scattered electrons mode (BSE), are presented in Figure 1. Their microstructures are all dendritic with the presence of $\mathrm{HfC}$ carbides (white) in their interdendritic spaces where they form a script-like eutectic compound with the austenitic matrix. The NiHf2 alloy also contains chromium carbides (darker than matrix). These microstructures were confirmed by XRay Diffraction using a Philips X'Pert Pro diffractometer (used wavelength: $\mathrm{Cu} \mathrm{K} \alpha$ 1.5406 Angströms)[10].

\subsection{The high temperature exposures and preparation of the metallographic samples}

Parallelepipeds of about $10 \mathrm{~mm} \times 10 \mathrm{~mm} \times 3 \mathrm{~mm}$ were cut in the ingots the thermogravimetry tests. They were polished with papers enriched with $\mathrm{SiC}$ particles paper grade varying from 120 or 240 to 1200 . Edges and corners were smoothed using the 1200-grit paper. They were exposed, in a resistive furnace, at $1200^{\circ} \mathrm{C}$ during 46 hours to a continuous flow $\left(1.5 \mathrm{~L} \mathrm{~h}^{-1}\right)$ of dry industrial air $\left(80 \% \mathrm{~N}_{2}-20 \% \mathrm{O}_{2}\right)$, after a heating phase achieved at $+20^{\circ} \mathrm{C} / \mathrm{min}$ and before a cooling phase realized at $5^{\circ} \mathrm{C} / \mathrm{min}$.

Just after cooling and before any metallographic preparation, the surface of the thermally aged samples were subjected to X-ray diffraction (XRD, Philips X'Pert Pro diffractometer) to identify the oxides developed externally and covering the samples. After this preliminary characterization the aged samples were covered by a thin layer of gold (cathodic sputtering) to obtain an external surface electrically conductive. A thick nickel coating was then deposited by cathodic polarization of the sample in a Watt's bath heated at $50^{\circ} \mathrm{C}$. The external oxide scale being thus protected against any mechanical stresses, each sample was cut in two parts which were then embedded in a cold resin mixture (resin CY230 + hardener HY956, ESCIL). The mounted samples were finally polished with the same successive SiCpapers as done above, but also ultrasonically cleaned and polished until reaching a mirror-like surface state as required for metallographic examinations.

\subsection{Bulk microstructure observations and hardness measurements}

The examination of the microstructures of the aged samples were realized using a SEM (JEOL JSM-6010LA) in BSE mode, at different magnifications. The 
particles were identified by EDS pinpoint measurements using the EDS device equipping the SEM, technique which was also used to specify the $\mathrm{Cr}$ and $\mathrm{Hf}$ contents in the matrix. Three $\times 1000$ BSE micrographs were notably taken per aged sample to perform surface fraction measurements by image analysis, using the Photoshop CS software of Adobe.

Vickers indentations were carried out in the bulk using a Testwell Wolpert device (load: $30 \mathrm{~kg}$ ). An average value and a standard deviation one were then obtained for each of the aged samples.

The same characterizations, particles' identification, pinpoint EDS in matrix, image analysis of carbides and indentations, were additionally realized on the as-cast samples of the alloys, to allow comparisons.

\subsection{Surface and sub-surface of the aged/oxidized alloys}

EDS measurements were performed with the same SEM on the thickness of the oxide scales seen in cross-section, to identify the present oxides and notably to verify if the scales are mainly composed of chromia. The same technique was used to specify the chromium (and hafnium) contents in extreme surface to verify whether the alloy is still chromia-forming and in the affirmative case if one can expect that the alloy will keep this chromia-forming behaviour a long time after these first 46 hours at this same temperature of $1200^{\circ} \mathrm{C}$.

EDS concentrations profiles were additionally realized to know the new distribution of chromium and of hafnium, and notably to know the depth over which the alloy is depleted in chromium.

\section{Results}

\subsection{Evolution of the bulk microstructures; consequences on hardness}

The initial microstructures and the ones in the aged condition are presented together in Figure 2. It appears that the hafnium carbides are still present, with globally the same morphology as initially. Chromium carbides have appeared in the $\mathrm{NiHf} 1$ and $\mathrm{NiHf3}$ alloys in which they were not present initially while the chromium carbides which initially existed in the NiHf2 alloy seem having almost disappeared. Concerning the $\mathrm{HfC}$ carbides again, one can also notice that there is a slight but visible decrease of their surface fractions. 
To quantitatively value the observed changes image analysis was performed and the obtained results are graphically presented in Figure 3. The surface fraction of $\mathrm{HfC}$ carbides (Figure 3, A) has effectively decreased in the three alloys, especially in the NiHf3 one in which chromium carbides have appeared in such quantities that it is in this third alloy that there are now the most present. Chromium carbides (Figure 3, B) have also appeared in the NiHf1 alloy in which they were not present initially. $\mathrm{NiHf2}$ is the single alloy in which the surface fraction in chromium carbides has decreased when compared to the as-cast microstructure in which they were present. The total surface fractions of carbides in the three alloys and their evolutions due to the high temperature exposure are presented in Figure $3(\mathrm{C})$. There is no significant evolution of this total fraction during the high temperature stage neither for the $\mathrm{NiHf1}$ alloy nor for the NiHf3 alloys. For these two alloys the surface fraction evolution of the hafnium carbides is more or less compensated by the chromium carbides' one. After high temperature exposure the NiHf3 alloy still contains more carbides than the Nif1 one. In contrast, at the same time there is for the NiHf2 alloy a significant decrease in total carbide surface fraction.

On another side it seems that the contents of the matrix in chromium and hafnium have evolved during the 46 hours spent at $1200^{\circ} \mathrm{C}$ (Figure 4). This is true for chromium for the NiHf2 and NiHf3 alloys for which the uncertainty bars are not overlapped but not evident for the NiHf1 alloy. The increase in chromium content in the bulk NiHf2 matrix is in good agreement with the partial disappearance of the chromium carbides existing initially while the decrease in matrix chromium content of the NiHf3 bulk well corresponds to the solid state precipitation of chromium carbides. Concerning the $\mathrm{Hf}$ content in matrix the base results were very variable in a same sample, between 0 (values probably really obtained in the matrix) and values up to $1 \mathrm{wt} . \% \mathrm{Hf}$ probably due to the proximity of subjacent $\mathrm{HfC}$ carbides. This led to extremely high values of standard deviation and one can reasonably think that the real $\mathrm{Hf}$ content in matrix is very low in all cases. It is nevertheless interesting to see that the $\mathrm{Hf}$ content in matrix, which seemed initially higher in the $\mathrm{Hf}$-richest $\mathrm{NiHf3}$ alloy, has perhaps increased a lot while the $\mathrm{HfC}$ carbide fraction has significantly decreased in this same alloy.

Vickers indentations were performed on the as-cast samples and on the aged ones. The results are graphically presented together in Figure 5 , to which are added 
hardness results measured in the same conditions for ternary alloys with the same chromium and carbon contents as the HfC-containing alloys studied here. One can see that for all alloys, for the Hf-containing ones as well as for the Hf-free ones, the $\left\{46 \mathrm{~h} ; 1200^{\circ} \mathrm{C}\right\}$ stage induced a decrease in hardness. This is due to the decrease in chromium carbide fraction for the ternary alloys and to the decrease in hafnium carbides for the alloys of this study. For the latter ones, the solid state appearance and growth of chromium carbides was obviously not sufficient to counterbalance the hardness decrease due to the HfC partial loss.

\subsection{Characterization of the oxidized states of the alloys}

As demonstrated by $\mathrm{X}$-ray diffraction before cross-section preparation the three samples are covered by essentially chromia, as illustrated by the diffractogram acquired on the NiHf2 oxidized surface given as example in Figure 6. XRD results also show that hafnium oxide is present too, but in small quantity. When examined in cross section (Figure 7) one can see that the oxide which has not been lost by spallation during cooling is essentially chromia, mixed here and there with small islands of $\mathrm{HfO}_{2}$ (of the monoclinic type according to XRD the diffractogram) Obviously, oxidation tended to penetrate in alloy in some locations. In contrast with cast alloys containing chromium carbides and even tantalum carbides the interdendritic network of hafnium carbides did not disappear from the oxidation front. This is very different from what is usually observed during the high temperature oxidation of alloys containing chromium carbides and/or tantalum carbides, for which a carbide-free zone develops over a depth which increases with time as well as with temperature, due to the liberation of chromium and/or tantalum which thereafter diffuse towards the oxidation front. Here the $\mathrm{HfC}$ carbides close to the alloy surface did not disappear to liberate hafnium: either they stay unchanged on place or the hafnium carbides are transformed in hafnium oxides in the same location as they were initially.

Two EDS concentration profiles were acquired through the subsurface from the \{alloy/external oxide\} interface for each oxidized sample. One of them is presented per alloy as example in Figure 8. They all start in the bulk with $\mathrm{Cr}$ contents slightly higher than the chromium contents of the whole alloys since all chromium is contained in the matrix (no chromium in the HfC carbides). One can see that the 
chromium on extreme surface and the Cr-depleted depths may depend on the alloy. These two characteristics were noted for the two EDS profiles acquired per sample and the average values are graphically given in Figure 9. One can see first that the chromium content on extreme surface tends to be higher for the NiHf2 alloy than for the two other alloys. Second the chromium depletion is obviously deeper for the NiHf1 alloy than for the two alloys which have the higher carbon contents then the higher fractions of interdendritic carbides. Concerning hafnium, the EDS concentration profiles of which were also plotted in Figure 8, one can observe that its content is often extremely low (even not detected) except in some locations where the electron obviously probe shot either a $\mathrm{HfO}_{2}$ oxide or a $\mathrm{HfC}$ carbides.

\section{Discussion}

These HfC-containing nickel-based alloys are thus not really stable at high temperature. Indeed, the microstructures formed during solidification do not correspond to the thermodynamic equilibrium at $1200^{\circ} \mathrm{C}$ and may necessarily evolve - as least a little - during the isothermal exposure which was applied to the alloy in this study. The surface fractions of the $\mathrm{HfC}$ carbides and of the chromium carbides present in the as-cast state have thus changed. A decrease in HfC surface fraction was noticed for the three $\mathrm{Hf}$-containing alloys. Simultaneously one observed an increase ( $\mathrm{NiHf} 1$ and $\mathrm{NiHf} 3$ ) or a decrease (NiHf2) in surface fraction of chromium carbides. These variations of carbides quantities were first qualitatively detected, and thereafter quantified by image analysis. Their consequences were here preliminarily noted on the room temperature hardness of the alloys. The loss of both $\mathrm{HfC}$ and chromium carbides for the NiHf2 alloy, and the replacement of a part of the hard $\mathrm{HfC}$ carbides (around $2900 \mathrm{Hv} 50 \mathrm{~g}$, [12]) by softer chromium carbides (around $1500 \mathrm{Hv} 50 \mathrm{~g}$, [12]) in the NiHf1 and NiHf3 alloy, explains the general loss in hardness due to high temperature exposure. However the global hardness hierarchy of these three alloys was not modified by comparison with the as-cast states. In contrast the morphology of the $\mathrm{HfC}$ carbides was not significantly changed, as it can be the case of the $\mathrm{TaC}$ carbides of other alloys, Co-based notably, which are generally much more fragmented by such exposure to high temperature with as results a general weakening of the mechanical properties at high temperature [13]. This should be not the case for these alloys since the script-like morphology of the interdendritic $\mathrm{HfC}$ 
carbides which are mixed with the periphery of the matrix dendrites in a eutectic compound is known to be favourable to creep-resistance notably.

Generally alloys and superalloys strengthened by interdendritic carbides of chromium and of tantalum, exposed to high temperature oxidation, are subjected to internal oxidation in $\mathrm{CrTaO}_{4}$ oxides close to the alloy/chromia interface and also to the disappearance of these carbides over a depth increasing with time at a given temperature [14]. In addition the inwards extension of this carbide-free zone is faster for a higher temperature [15] and this may lead to a depth not reinforced by carbides which can be of several tens of micrometers. It can be for example more than $70 \mu \mathrm{m}$ for a Co(bal.)-8Ni-30Cr-0.4C-6Ta (wt.\%) after $100 \mathrm{~h}$ in air at $1200^{\circ} \mathrm{C}$ [16]. In the present study internal oxides $\left(\mathrm{HfO}_{2}\right.$ but also chromia) have formed close to the extreme surface but no such carbide-free zone developed inwards. Thus, if the presence of internal oxides can threaten the mechanical resistance of the external alloy zone (which may be particularly solicited by tensile stress induced by flexural deformation for example) the strengthening by carbides of the just inner zone still exists.

Concerning the most external part of the oxides formed - the oxide scale covering the alloy - it appears that it is mainly composed of chromia. This protective oxide, unfortunately partly lost during the cooling, allowed the alloys oxidizing rather slowly and the presence of so high quantities in the very reactive element that is hafnium was not detrimental for the intrinsic good behaviour of the $\{\mathrm{Ni}-25 \mathrm{Cr}-0.25$ or $0.50 \mathrm{C}\}$ base alloys, in contrast with what was observed for similar chromium-rich cobalt-based alloys also very rich in $\mathrm{HfC}$ carbides [17]. After 46 hours at $1200^{\circ} \mathrm{C}$ the chromium content in extreme surface is not lower than 22 wt.\% this meaning that the chromia-forming behaviour of these nickel-based alloys will be surely maintained during an additional long time after these first 46 hours. One can remind that the chromium content in extreme surface is slightly higher for the NiHf2 alloy which was the single alloy out of the three ones which initially contained chromium carbides in its interdendritic spaces, as is to say rapidly available chromium reservoirs in the easy diffusion paths. However it is possible that the presence of hafnium carbides represented a hindrance to chromium diffusion since the $\mathrm{Cr}$-depleted zone was the lowest in the two alloys in which the $\mathrm{HfC}$ carbides were the most present (NiHf2 and $\mathrm{NiHf3).}$ 


\section{Conclusions}

Thus, the studied chromium-rich nickel-based alloys which contained rather dense interdendritic $\mathrm{HfC}$ networks were not really stable just after solidification but the greatest part of the $\mathrm{HfC}$ population was preserved during this rather long stage at high temperature. In contrast the chromium carbides that appeared in small quantities during solidification or the post-solidification solid state cooling in one of the alloys, and in higher quantities during the isothermal exposure in the two other alloys, showed that the chemical composition should be optimized to avoid the appearance of such carbides known to lower the solidus temperature (in TaCcontaining cobalt-based alloys for example) and then potentially detrimental for the high temperature properties. The refractoriness of the present alloys remains notably to specify, as well as their mechanical properties at high temperature as tensile behaviour or creep-resistance. These points will be the subjects of further investigations.

\section{Acknowledgements}

The author wishes to thank P. Villeger for the X-Ray Diffraction runs.

\section{References}

[1] Bradley, E.F. (1988) Superalloys: A Technical Guide, pp. 44-45, ASM International, Metals Park.

[2] Sims, C.T. (1972) Cobalt-Base Alloys. In: Sims, C.T. and Hagel, W.C. (eds), The Superalloys, pp. 150-174. John Wiley \& Sons, New York.

[3] Kofstad, P. (1988) High Temperature Corrosion, Elsevier Applied Science, London.

[4] Donachie, M.J. and Donachie, S.J. (2002) Superalloys, A Technical Guide (2 ${ }^{\text {nd }}$ edition), ASM International, Materials Park.

[5] Young, D.J. (2008) High Temperature Oxidation and Corrosion of Metals ( $1^{\text {st }}$ edition), Elsevier Corrosion Series, Amsterdam. 
[6] Berthod, P., Aranda, L., Vébert, C. and Michon, S. Experimental and Thermodynamic Study of the Microstructural State at High Temperature of Nickel base Alloys containing Tantalum. Calphad, 28, 159-166 (2004).

[7] Michon, S., Berthod, P., Aranda, L., Rapin, C., Podor, R. and Steinmetz, P. Application of thermodynamic calculations to study high temperature behavior of TaC-strengthened Co-base superalloys. Calphad, 27(3), 289-294 (2003).

[8] Berthod, P., Michon, S., Aranda, L., Mathieu, S. and Gachon, J.C. Experimental and thermodynamic study of the microstructure evolution in cobalt-base superalloys at high temperature. Calphad, 27(4), 353-359 (2003).

[9] Berthod, P. High temperature properties of several chromium-containing Cobased alloys reinforced by different types of $M C$ carbides $(M=T a, N b, H f$ and/or Zr). Journal of Alloys and Compounds, 481, 746-754 (2009).

[10] Berthod, P. Hafnium carbides in cast chromium-rich refractory alloys. Part 1: Case of nickel-based alloys. Materials Science: An Indian Journal, 9(9), 359365 (2013).

[11] Bouhanek, K., Oquab, D., Pieraggi, B. High-temperature oxidation of singlecrystal Ni-base superalloys. Materials Science Forum, 251-254, 33-40 (1997).

[12] Samsonov, G.V. (1964) High Temperature Materials №2: Properties Index, Plenum Press, New York.

[13] Michon, S., Aranda, L., Berthod, P. and Steinmetz, P. High temperature evolution of the microstructure of a cast cobalt base superalloy. Consequences on its thermomechanical properties. La Revue de Métallurgie/C.I.T. Science des Matériaux, 651-662 (2004).

[14] Berthod, P., Raude, S., Renck, A.S., Rapin, C., Podor, R. and Steinmetz, P. Influence of the microstructural texture of cast superalloys on their hightemperature oxidation behaviour. Materials Science Forum, 461-464, 11731180 (2004).

[15] Berthod, P., Aranda, L. and Vébert, C. Etude cinétique de l'oxydation à haute température et de la volatilisation de la chromine pour des superalliages de fonderie renforcés par carbures. Partie II: Cas d'alliages à base de nickel 
contenant du tantale. Annales de Chimie - Science des Matériaux, 31(2), 213235 (2006).

[16] Berthod, P., Raude, S. and Chiaravalle, A. Etude cinétique de l'oxydation à haute température et de la volatilisation de la chromine pour des superalliages de fonderie renforcés par carbures. Partie II : Cas de superalliages à base de cobalt et influence de la finesse dendritique. Annales de Chimie - Science des Matériaux, 31(2), 237-258 (2006).

[17] Conrath, E. and Berthod, P. Kinetics of high temperature oxidation of chromium-rich HfC-reinforced cobalt-based alloys. Corrosion Engineering Science and Technology (formerly: British Corrosion Journal), available on-line at http://dx.doi.org/10.1179/1743278213Y.0000000105 (25.07.2013). 

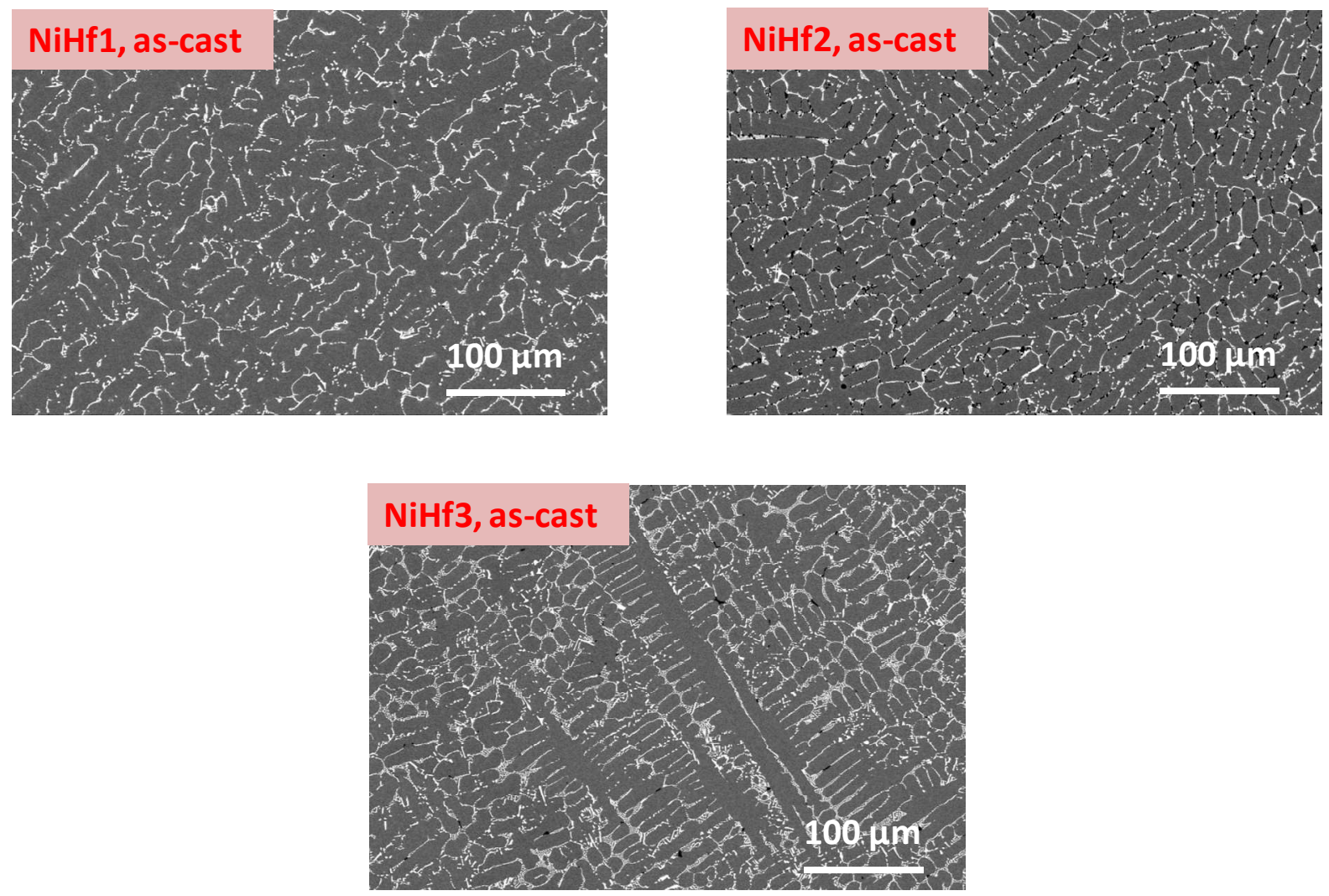

Fig. 1. Micrographs of the studied HfC-containing Nickel-based alloys (Scanning electron microscope, back scattered electrons mode) 

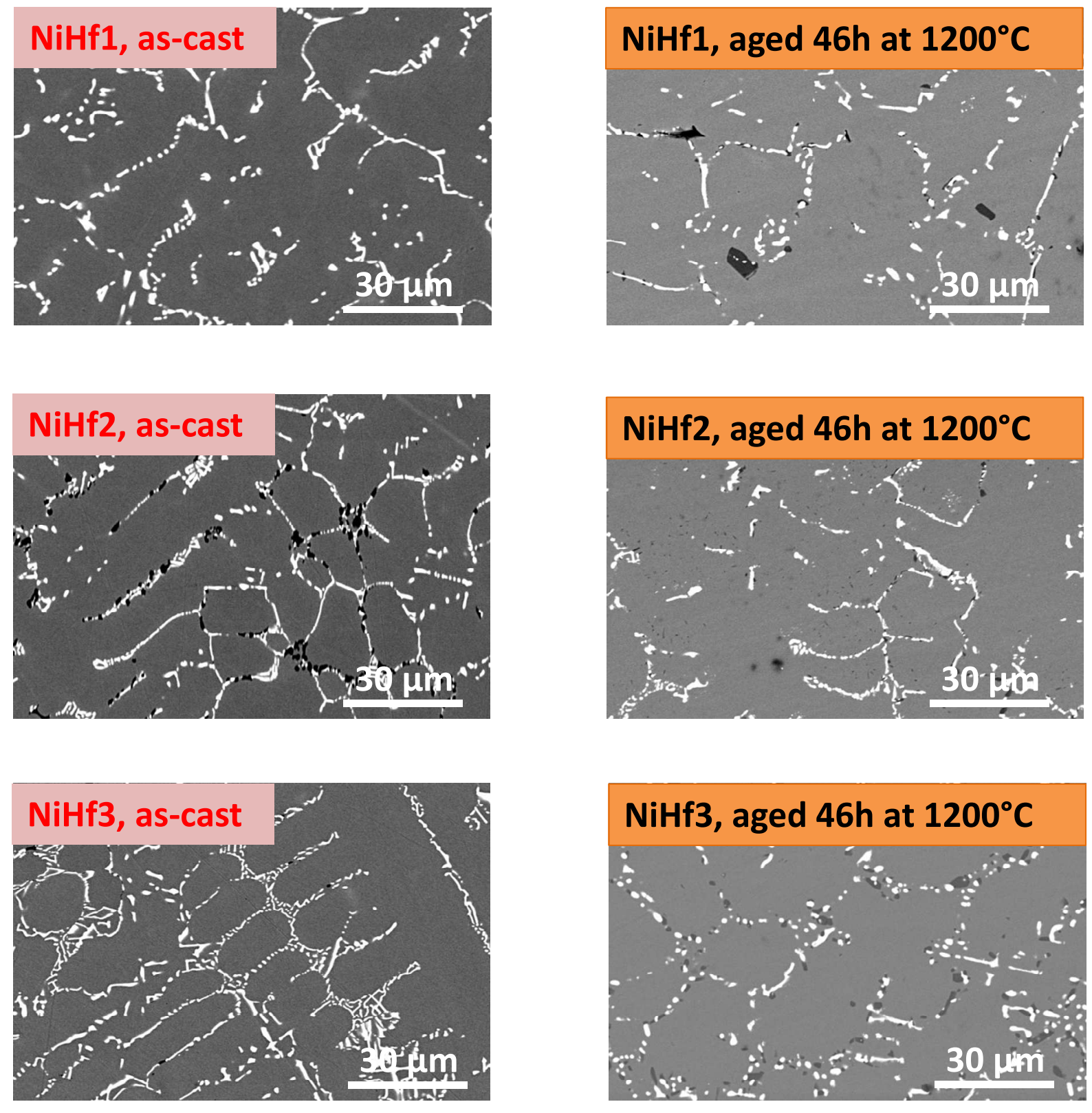

Fig. 2. Microstructures of the aged alloys (on the right) and recall of the initial ones (on the left) for comparison (SEM/BSE micrographs) 

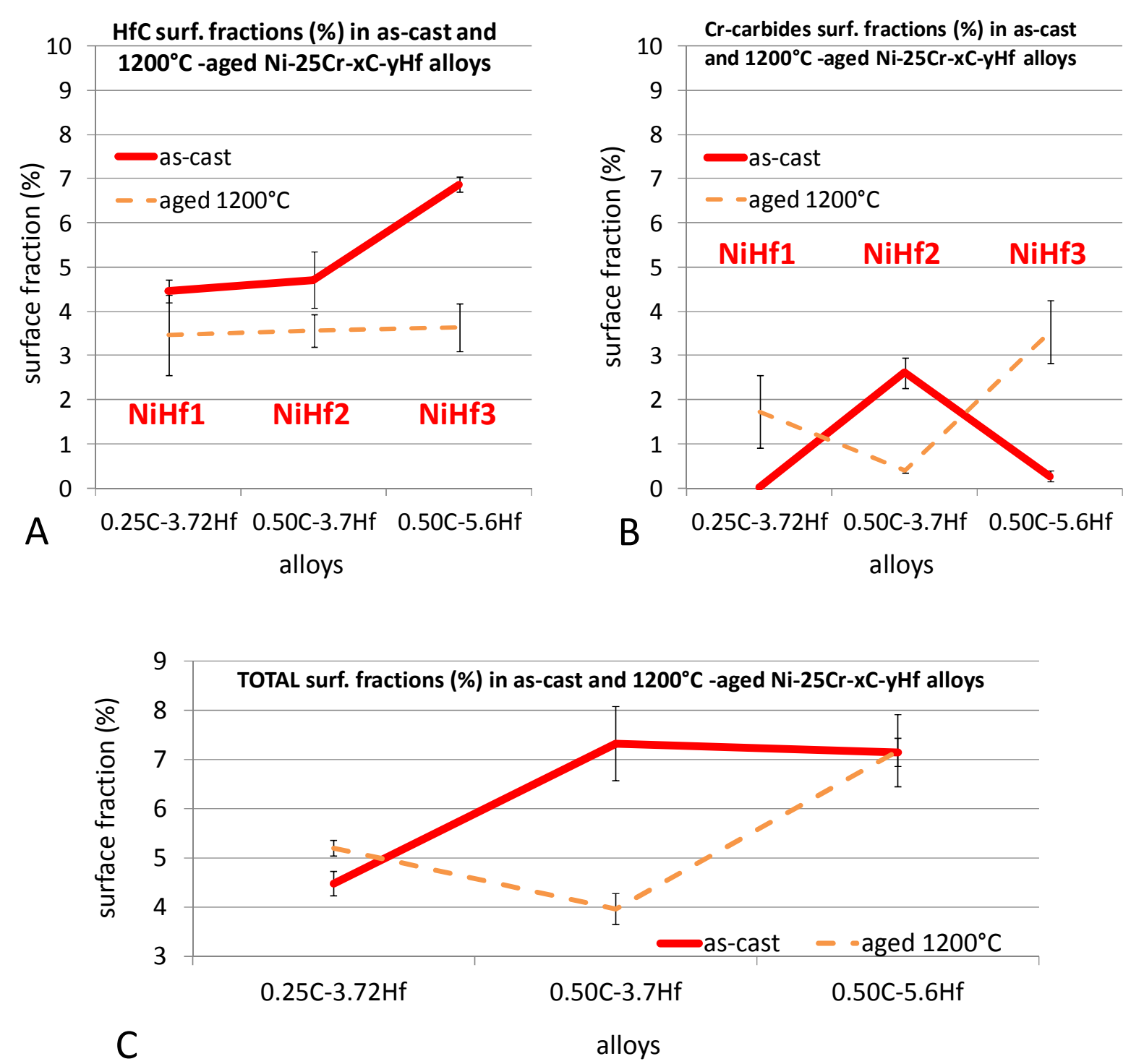

Fig. 3. Evolution of the surface fractions of the hafnium carbides $(A)$, of the chromium carbides $(B)$ and of the total surface fraction of carbides $(C)$ in the three alloys during the $46 \mathrm{~h}$-exposure at $1200^{\circ} \mathrm{C}$ (average and standard deviation values calculated from three image analysis measurements) 

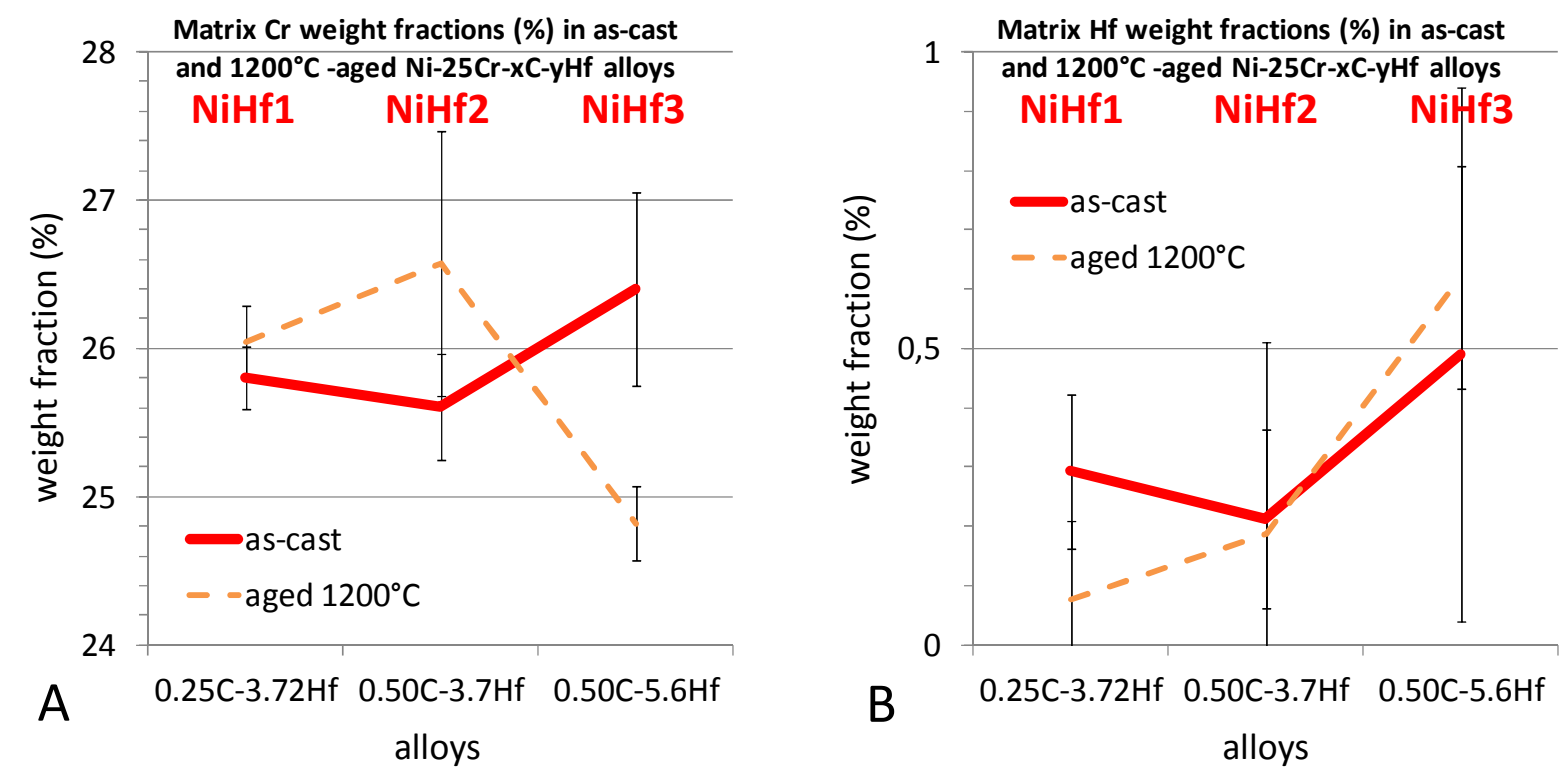

Fig. 4. Evolution of the chromium (A) and hafnium (B) contents in the bulk matrixes of the three alloys during the $46 \mathrm{~h}$-exposure at $1200^{\circ} \mathrm{C}$ (average $(\mathrm{Cr}, \mathrm{Hf})$ and standard deviation (Cr only) values determined by EDS pinpoint measurements) 


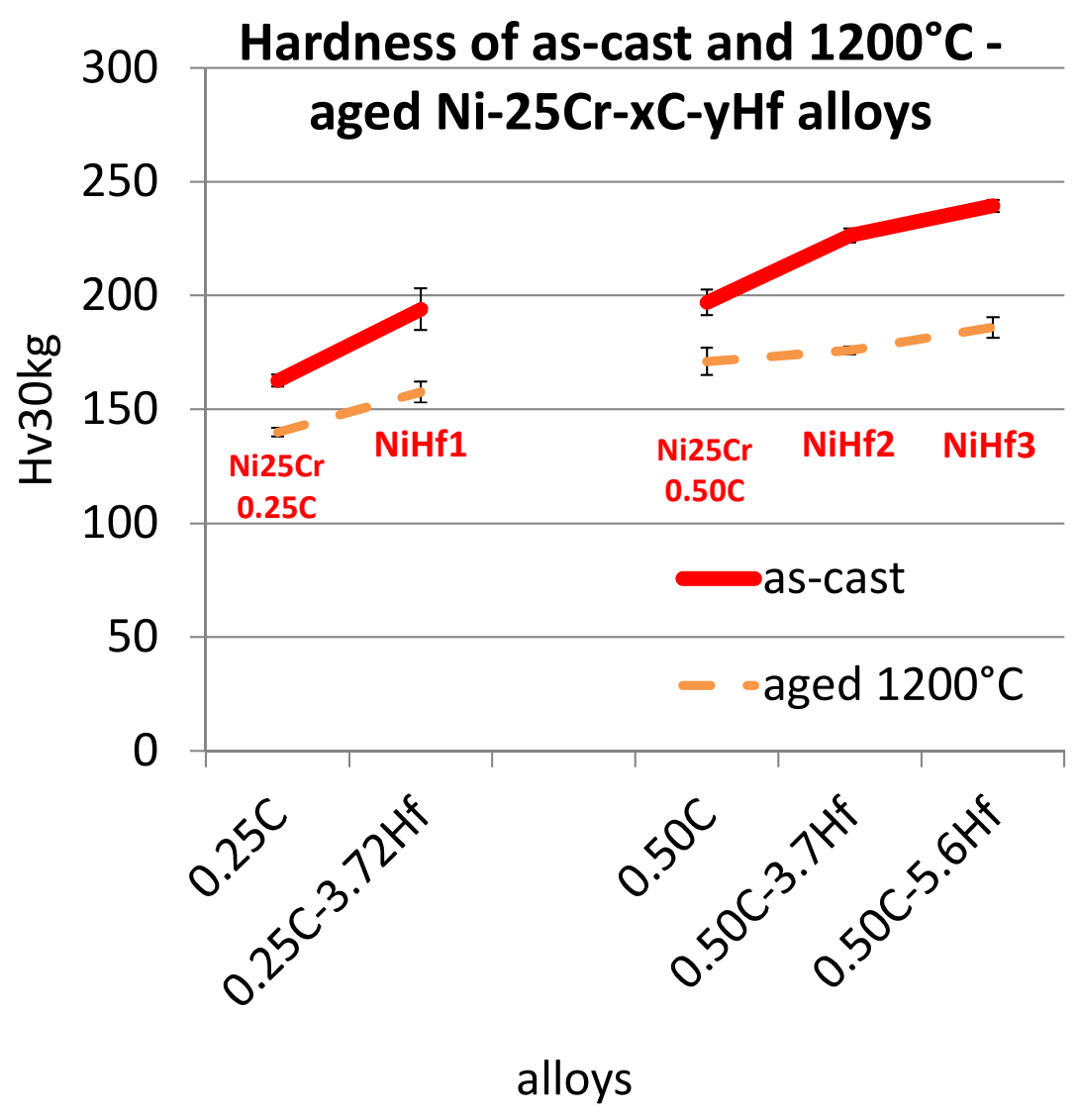

Fig. 5. Evolution of the Vickers hardness (load $30 \mathrm{~kg}$ ) of the three alloys during the $46 \mathrm{~h}$-exposure at $1200^{\circ} \mathrm{C}$ (average and standard deviation values calculated from three values); comparison with the same type of results obtained with $\mathrm{Hf}$-free ternary $\mathrm{Ni}-25 \mathrm{Cr}-\mathrm{xC}$ alloys with the same $\mathrm{C}$ contents) 


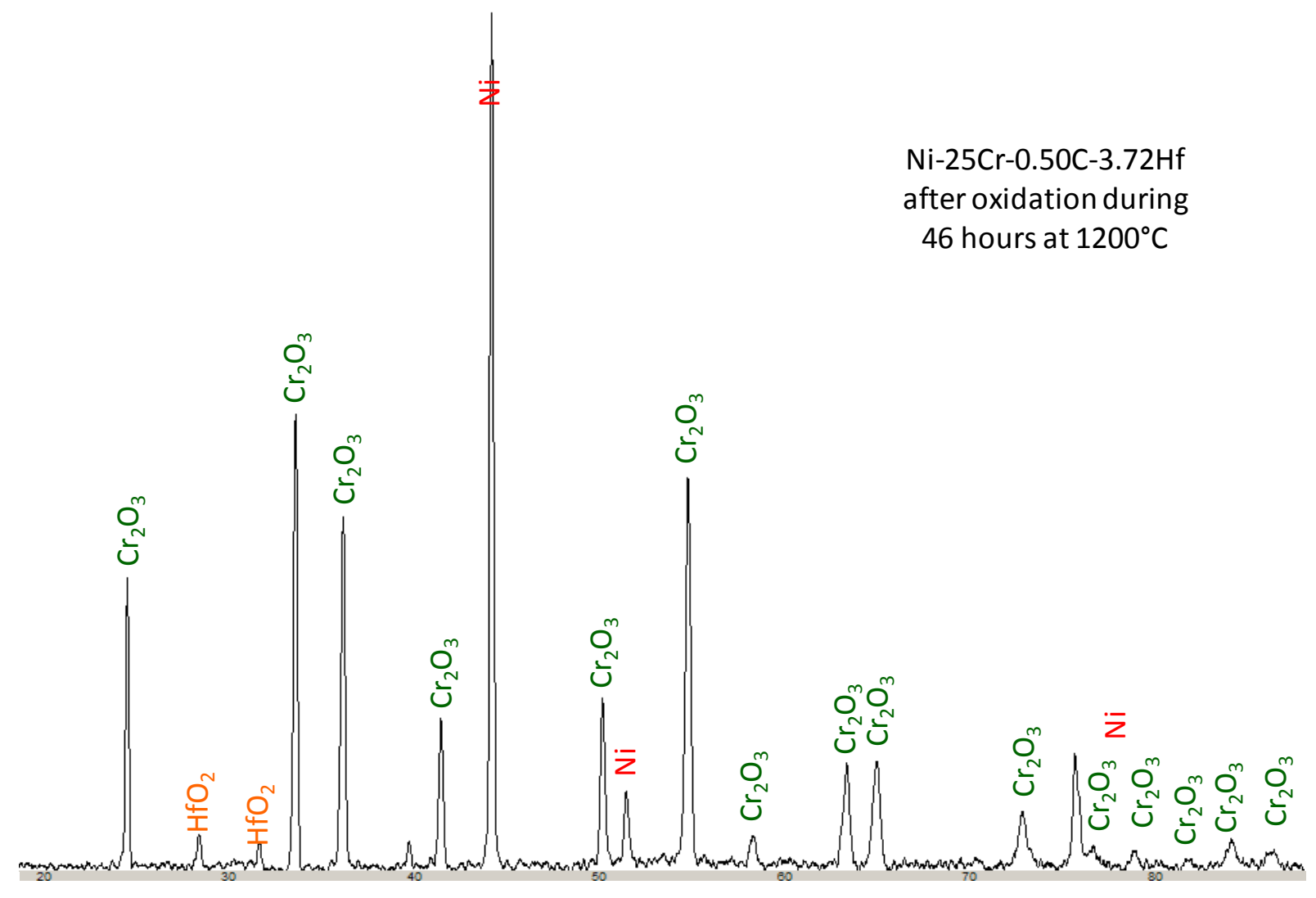

Fig. 6. Diffractogram acquired on the oxidized surface of the NiHf2 alloy 

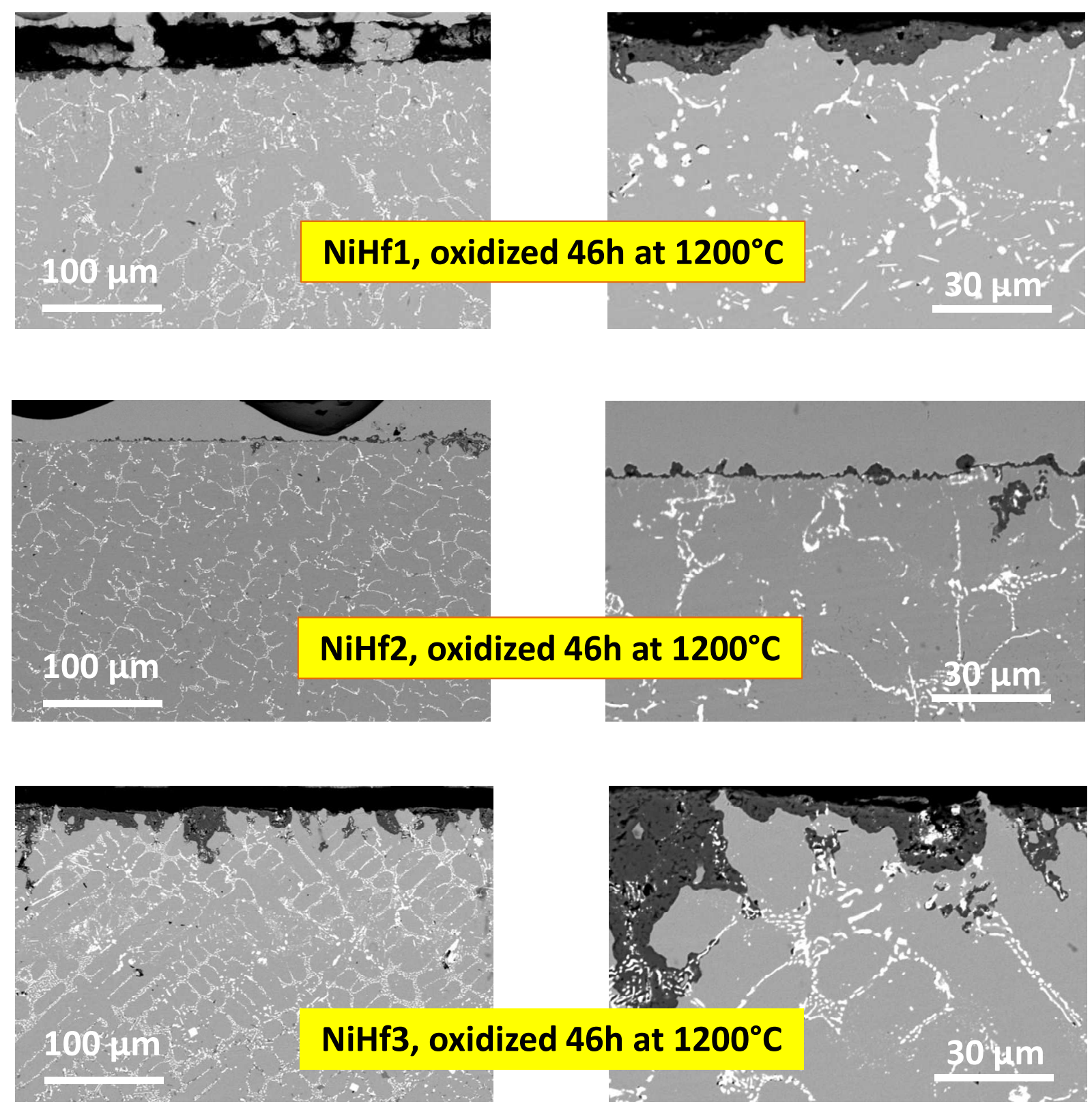

Fig. 7. Surface and sub-surface states of the three alloys as observed with the SEM in BSE mode (two magnifications: general view and enlargement) 

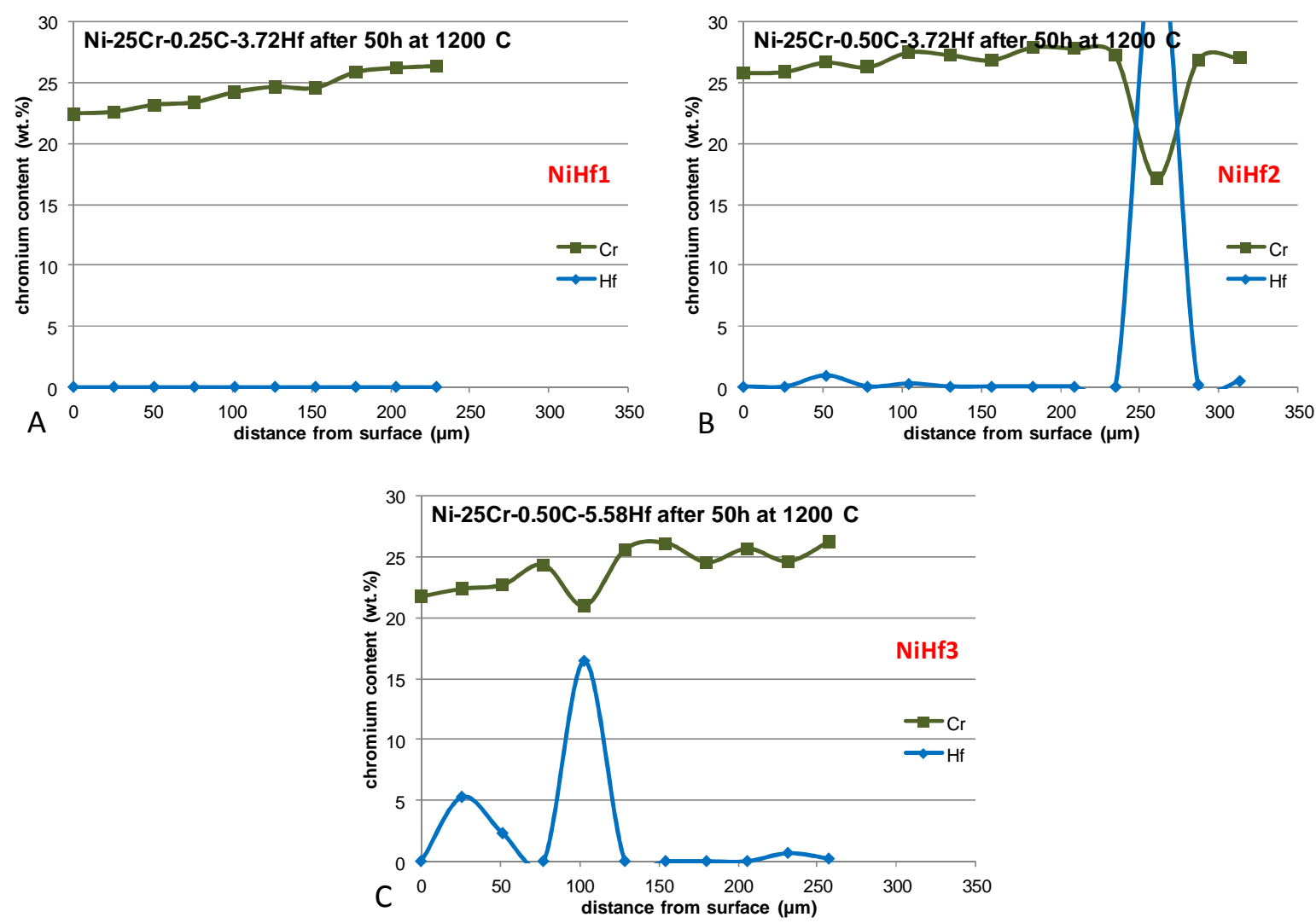

Fig. 8. EDS concentration profiles ( $\mathrm{Cr}$ and $\mathrm{Hf}$ ) across the subsurface of the oxidized $\mathrm{NiHf1}(\mathrm{A}), \mathrm{NiHf} 2(\mathrm{~B})$ and $\mathrm{NiHf3}(\mathrm{C})$ alloys 


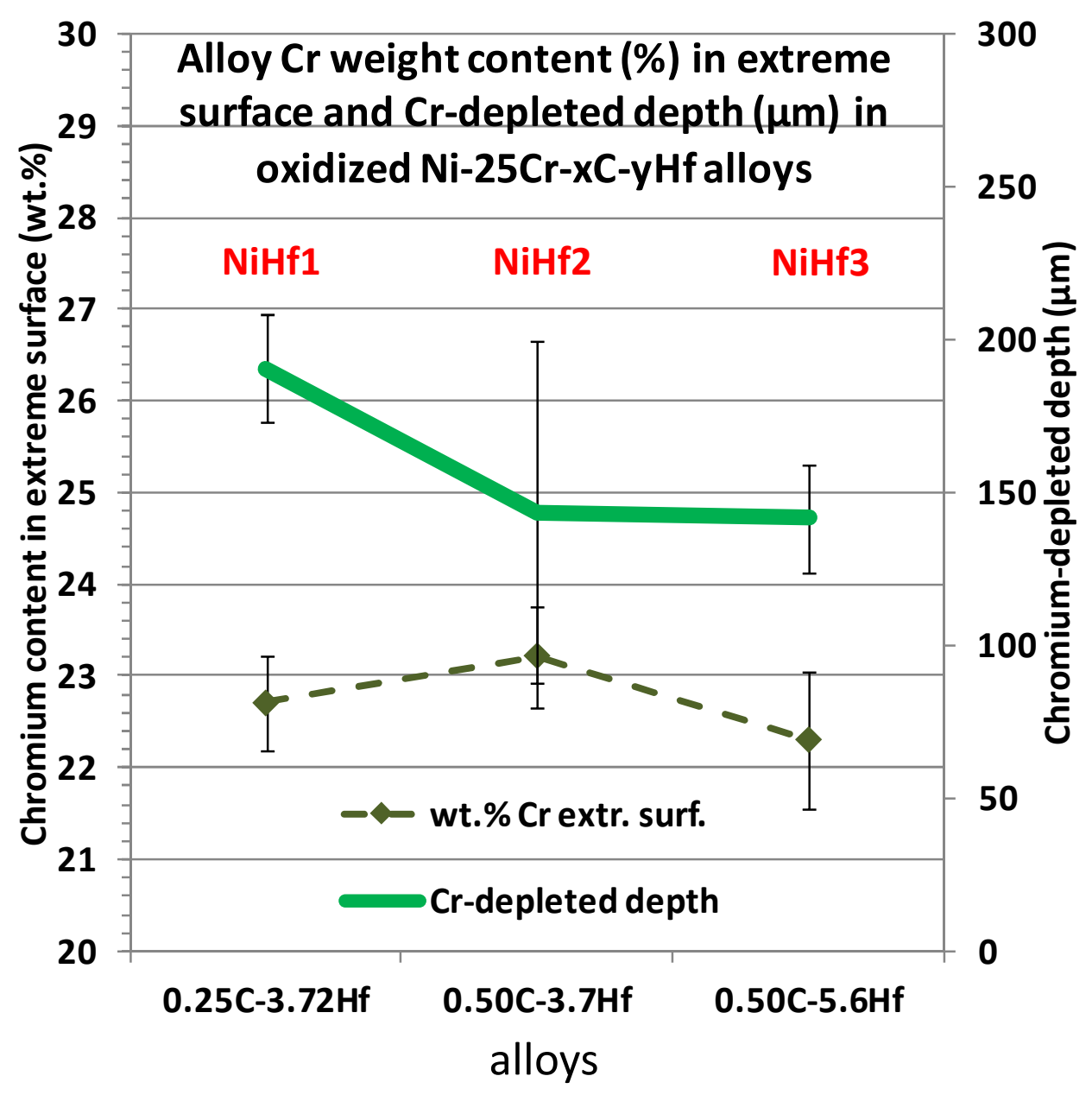

Fig. 9. Evolution of the chromium content in extreme surface and of the chromiumdepleted depth of the three alloys during the $46 \mathrm{~h}$-exposure at $1200^{\circ} \mathrm{C}$ (average and standard deviation values calculated from two values) 